\title{
Connexin 43 Delimits Functional Domains of Neurogenic Precursors in the Spinal Cord
}

\author{
Raúl E. Russo, ${ }^{1}$ Cecilia Reali, ${ }^{1}$ Milka Radmilovich, ${ }^{3}$ Anabel Fernández, ${ }^{2,4}$ and Omar Trujillo-Cenóz ${ }^{2}$ \\ ${ }^{1}$ Neurofisiología Celular y Molecular and ${ }^{2}$ Neuroanatomía Comparada, Instituto de Investigaciones Biológicas Clemente Estable, CP 11600 Montevideo, \\ Uruguay, ${ }^{3}$ Departamento de Histología y Embriología, Facultad de Medicina, CP 11800 Montevideo, Uruguay, and ${ }^{4}$ Unidad Asociada Neuroanatomía, \\ Facultad de Ciencias, CP 11400 Montevideo, Uruguay
}

The cells lining the central canal (CC) of the spinal cord derive from the ventral part of the neural tube and, in some vertebrates, are responsible for the functional recovery after spinal cord injury. The region that surrounds the $\mathrm{CC}$ in the turtle contains proliferating cells that seem to generate both glia and neurons. Understanding the biology of spinal progenitors with the potential to generate new neurons "in situ" is important for cell replacement therapies. Here, we aimed to identify and characterize precursor cells in the spinal cord of Trachemys dorbignyi. To evaluate the population of proliferating cells, 5-bromo-2' -deoxyuridine (BrdU) was injected every $4 \mathrm{~h}(50 \mu \mathrm{g} / \mathrm{g}$, i.p.) during $24 \mathrm{~h}$. We found $\mathrm{BrdU}^{+}$nuclei around the $\mathrm{CC}$ with a higher density in the lateral quadrants, in which whole-cell patch-clamp recordings showed extensive dye coupling of cells. Carbenoxolone $(100 \mu \mathrm{M})$ increased the input resistance, suggesting strong gap junction coupling among precursors. The expression of brain lipid binding protein (a marker of a subtype of radial glia) and Pax6 matched the location of clusters, suggesting these cells belonged to a domain of neurogenic precursors. These domains were delimited by a high density of connexin 43 (Cx43) located on the endfeet of CC contacting cells. Our findings indicate that spinal precursors share basic properties with those in the embryo and neurogenic niches of the adult brain, and support a key role of functional clustering via $\mathrm{Cx} 43$ in spinal cord neurogenesis.

Key words: radial glia; neurogenic precursors; brain lipid binding protein; Pax6; connexin 43; spinal cord

\section{Introduction}

The cells lining the central canal (CC) of the spinal cord derive from the ventral part of the neural tube (Fu et al., 2003) and thus may have retained some of the properties of embryonic precursors. Indeed, CC contacting cells proliferate in the adult rat (Horner et al., 2000), a process boosted by spinal cord injury (Mothe and Tator, 2005), but the differentiation from these spinal precursors toward the neuronal lineage appears forbidden (Horner et al., 2000). Recent reports, however, suggest that new neurons can be generated from CC contacting cells as a response to some forms of injury (Danilov et al., 2006). Understanding the biology of spinal progenitors with the potential to generate new neurons "in situ" is fundamental for the design of cell replacement therapies.

During the development of the cerebral cortex, radial glia (RGs) behave as precursors dividing vigorously to generate neurons that migrate along RG processes (Noctor et al., 2001). These precursors have a characteristic molecular and functional phenotype, expressing cell specific proteins and lacking active mem-

Received Dec. 28, 2007; revised Feb. 14, 2008; accepted Feb. 16, 2008.

This work was supported by National Institutes of Neurological Disorders and Stroke-National Institutes of Health Grant NS048255 (R.E.R.). We thank Dr. J.C. Sáez for kindly providing the antibody against connexin 43 and Dr. Alberto Pereda for critical reading of this manuscript. We thank M. I. Rehermann for technical assistance.

Correspondence should be addressed to Dr. Raúl E. Russo, Neurofisiología Celulary Molecular, Instituto de Investigaciones Biológicas, Clemente Estable, Avenida Italia 3318, CP 11600 Montevideo, Uruguay. E-mail: rrusso@iibce.edu.uy.

DOI:10.1523/JNEUROSCI.5736-07.2008

Copyright $\odot 2008$ Society for Neuroscience $\quad$ 0270-6474/08/283298-12\$15.00/0 brane properties (Hartfuss et al., 2001; Noctor et al., 2002). Another feature of precursors is their functional clustering via gap junction coupling (Lo Turco and Kriegstein, 1991; Bittman et al., 1997; Noctor et al., 2001, 2002), which appears critical for maintenance of their phenotype and capacity to proliferate (Bruzzone and Dermietzel, 2006). The progenitors in neurogenic niches of the adult brain derive from their counterpart in the embryo and share many of their fundamental properties (Ming and Song, 2005; Lledo et al., 2006). However, the properties of potential precursors in the mature spinal cord remain elusive.

Progenitor cells and neuroblasts persist in the postnatal spinal cord of the turtle (Fernández et al., 2002; Russo et al., 2004), which thus represents a unique model to study the biology of spinal neurogenic precursors. We hypothesize that spinal precursors share basic mechanisms with those in well characterized neurogenic niches of the adult brain. Here, we take advantage of this unique model to study the nature of precursor cells in the spinal cord. We combined a 5-bromo-2'-deoxyuridine (BrdU) saturation protocol to identify the population of proliferating cells, with patch recording of cells around the CC and molecular phenotyping. We found that the higher rate of proliferation occurred in the lateral CC in which extensive clusters of gap junction coupled cells existed. The expression of brain lipid binding protein (BLBP) [a marker of RGs (Feng et al., 1994)] and Pax6 [a marker of neurogenic precursors (Pinto and Götz, 2007)] matched the location of clusters, indicating that these cells belonged to a domain of neurogenic progenitors. These domains of precursor 
cells were spatially delimited by connexin 43 (Cx43) expression on the apical segments of CC contacting cells. Our findings represent the first evidence showing that precursor cells in the spinal cord share fundamental properties with those in the embryo and canonical neurogenic niches of the adult mammalian and avian brains, and support a key role of functional coupling via gap junctions as a basic, phylogenetically preserved mechanism in neurogenic precursors.

\section{Materials and Methods}

General. Juvenile turtles (Trachemys dorbignyi; 5-7 cm carapace length) were used following the guidelines of our local Committee for Animal Care and Research (Comisión Honoraria de Experimentación Animal, Universidad de la República, Montevideo, Uruguay). The animals were kept in temperate aquaria at $26-30^{\circ} \mathrm{C}$ under natural illumination conditions.

BrdU labeling. To reveal the population of proliferating cells, we used a cumulative BrdU protocol (Nowakowski et al., 1989). Turtles $(n=5)$ received seven intraperitoneal injections of $\operatorname{BrdU}(50 \mu \mathrm{g} / \mathrm{g}$ body weight; Sigma-Aldrich, St. Louis, MO) dissolved in $0.9 \% \mathrm{NaCl}$, which was $0.007 \mathrm{~N}$ for $\mathrm{NaOH}$, in a time lapse of $24 \mathrm{~h}$. According to Cameron and McKay (2001), the dose used here supplies most DNA-synthesizing cells with enough BrdU to appear unambiguously labeled (Taupin, 2007). Because cycling cells in the spinal cord have a long cell cycle (Horner et al., 2000), we assumed a $4 \mathrm{~h}$ interval between injections was enough to label the whole population of proliferating cells during $24 \mathrm{~h}$. Animals were killed $4 \mathrm{~h}$ after the last injection and spinal cord living slices were obtained as described below. Quantification studies were made in another series of experiments $(n=4)$ using the same injection protocols but the turtles were fixed by perfusion, and sections $(50-80 \mu \mathrm{m}$ thick) from the spinal cord cut with a vibrating microtome.

Slice preparation and electrophysiology. Turtles anesthetized by hypothermia were decapitated and the blood was removed by intraventricular perfusion with Ringer's solution $\left(6^{\circ} \mathrm{C}\right)$. The cervical enlargement was dissected out and transverse $300-\mu \mathrm{m}$-thick slices were cut, placed in a chamber ( $1 \mathrm{ml}$ volume), and superfused $\left(1 \mathrm{ml} \mathrm{min}^{-1}\right)$ with Ringer's solution of the following composition (in $\mathrm{mm}$ ): $96.5 \mathrm{NaCl}, 2.6 \mathrm{KCl}, 31.5$ $\mathrm{NaHCO}_{3}, 3 \mathrm{CaCl}_{2}, 2 \mathrm{MgCl}_{2}$, and 10 glucose. The solution was saturated with $5 \% \mathrm{CO}_{2}$ and $95 \% \mathrm{O}_{2}, \mathrm{pH}$ 7.6. All experiments were performed at room temperature. Cells were visualized with differential interference contrast (DIC) optics (DM LFS; Leica, Wetzlar, Germany) with a $40 \times$ (0.8 numerical aperture) objective. Patch-clamp whole-cell recordings were obtained with electrodes filled with the following (in $\mathrm{mm}$ ): 122 K-gluconate, $5 \mathrm{Na}_{2}$-ATP, $2.5 \mathrm{MgCl}_{2}, 0.003 \mathrm{CaCl}_{2}, 1 \mathrm{EGTA}, 5.6 \mathrm{Mg}$ gluconate, 5 K-HEPES, 5 H-HEPES, and 10 biocytin, pH 7.4, 5-10 M $\Omega$. In some cases, Lucifer yellow (0.1\%; Sigma-Aldrich), Alexa 488 hydrazide $(500 \mu \mathrm{M})$, or Alexa 488 dextran $(500 \mu \mathrm{M}$; molecular weight 10,000; Invitrogen, Eugene OR) were added to the pipette solution. Current- and voltage-clamp recordings were performed with an Axoclamp 2B or a Multiclamp 700B (Molecular Devices, Palo Alto, CA). Current and voltage steps were generated with the pClamp10 package (Molecular Devices), which was also used for additional analysis. Series resistance and whole-cell capacitance were not compensated. In voltage-clamp mode, cells were held at $-70 \mathrm{mV}$ and the resting membrane potential was estimated from the current-voltage relationship (at $I=0$ ). To subtract leak currents, we used a $\mathrm{P} 4$ protocol provided by Clampex10 software that allowed simultaneous storage of raw and leak subtracted data. Liquid junction potentials were determined and corrected (Barry and Diamond, 1970). Values are expressed as the mean \pm SEM.

Carbenoxolone (Cbx) (100 $\mu \mathrm{M})$ or meclofenamic acid (MFA) (100 $\mu \mathrm{M})$ were added to normal Ringer's to block gap junctions, whereas tetraethylammonium (TEA) $(10 \mathrm{~mm})$ was added to block $\mathrm{K}^{+}$channels. All drugs were purchased from Sigma-Aldrich.

Morphological identification of recorded cells. During whole-cell patchclamp recordings, 109 cells were filled with biocytin. Cells were filled for at least $10 \mathrm{~min}$ and the slices were fixed by immersion in $4 \%$ paraformaldehyde in $0.1 \mathrm{M}$ phosphate buffer (PB) for 12-24 h. In some cases, cells were visualized in living slices by injecting Lucifer yellow or Alexa 488
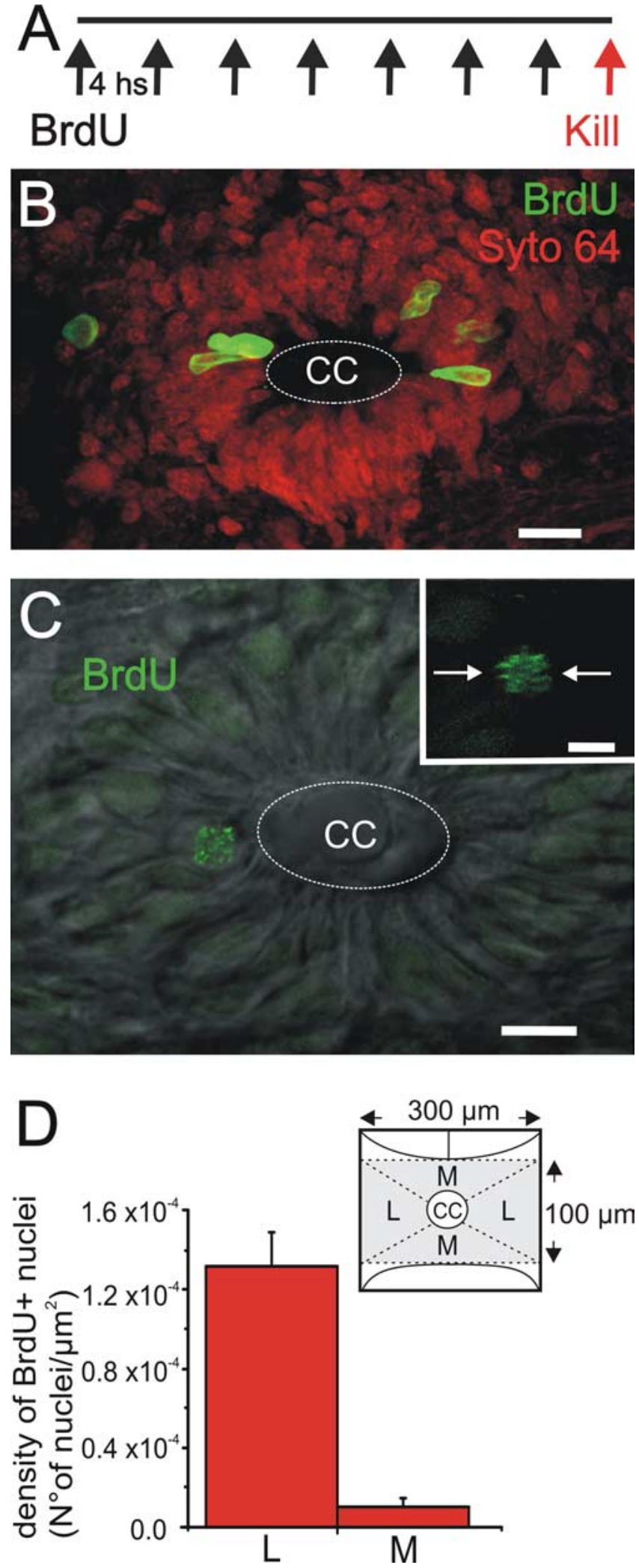

Figure 1. The $C G$ as a proliferative niche. $A$, Scheme of the BrdU protocol used. $B, \mathrm{BrdU}^{+}$cells (green) concentrated on the lateral aspects of the region surrounding the CC. Syto 64 (red) was used to stain nuclei. C, BrdU ${ }^{+}$cell in telophase (confocal section and DIC illumination) close to the (C. The inset shows the plane of cleavage (arrows). $\boldsymbol{D}$, Densities of BrdU-labeled nuclei in the lateral $(\mathrm{L})$ and medial $(\mathrm{M})$ aspects of the region surrounding the $C($ (mean $\pm S E M)$. The drawing shows schematically the limits of the regions (shaded area) in which $\mathrm{BrdU}^{+}$nuclei were counted. Scale bars: $\boldsymbol{B}, 10 \mu \mathrm{m} ; \boldsymbol{C}, 20$ $\mu \mathrm{m}$; inset, $10 \mu \mathrm{m}$. 

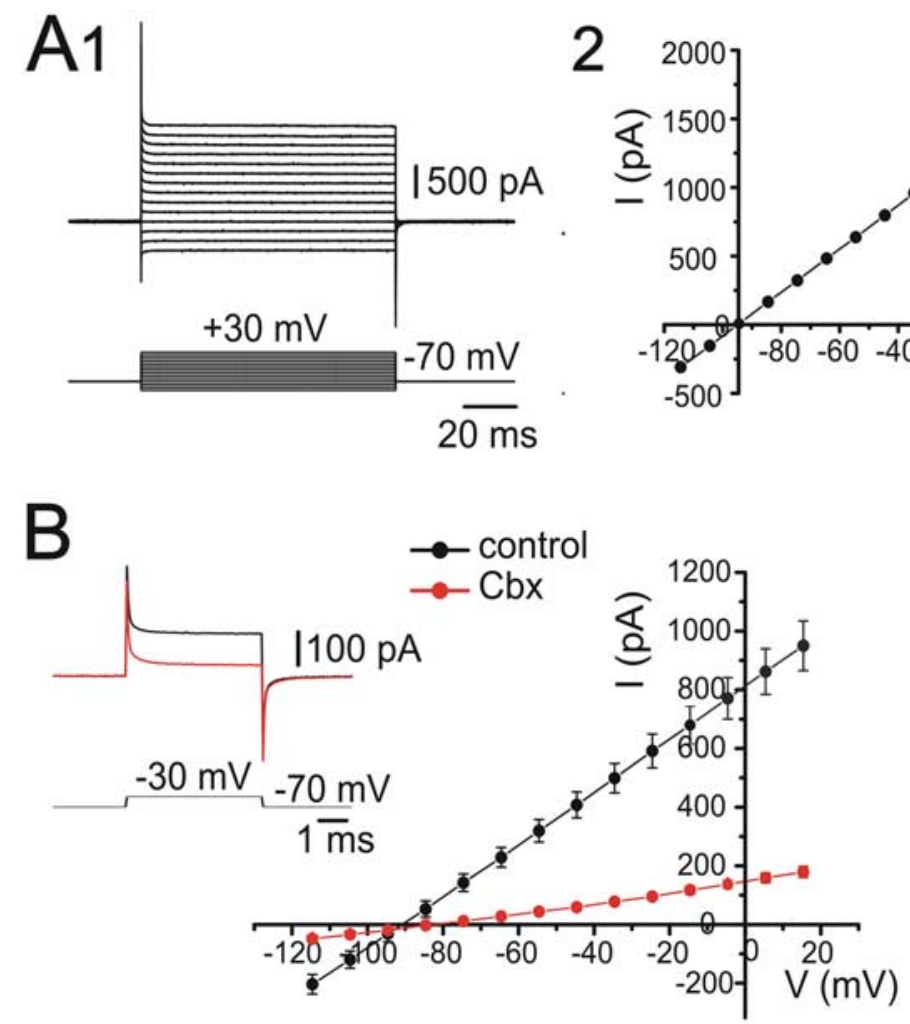
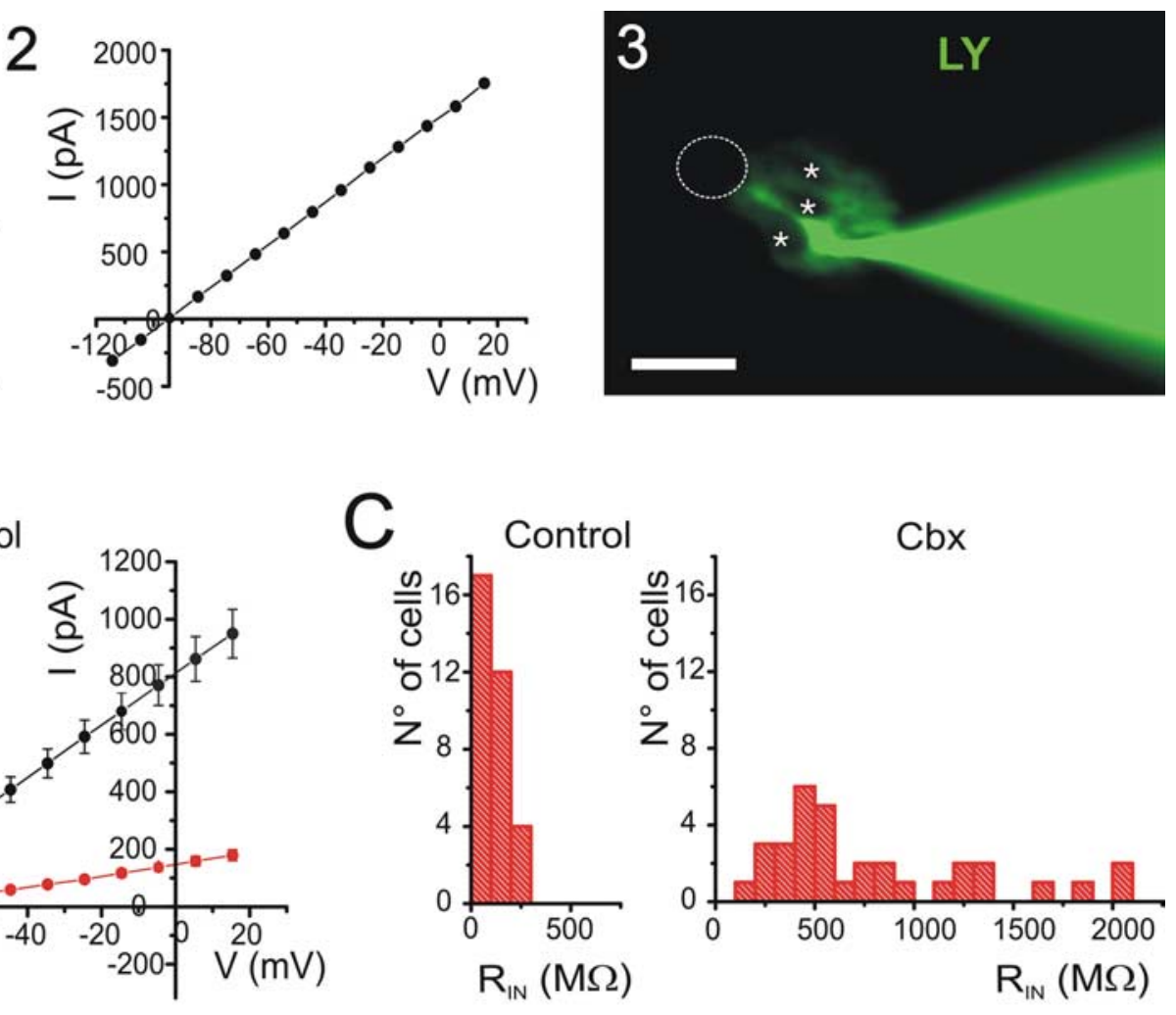
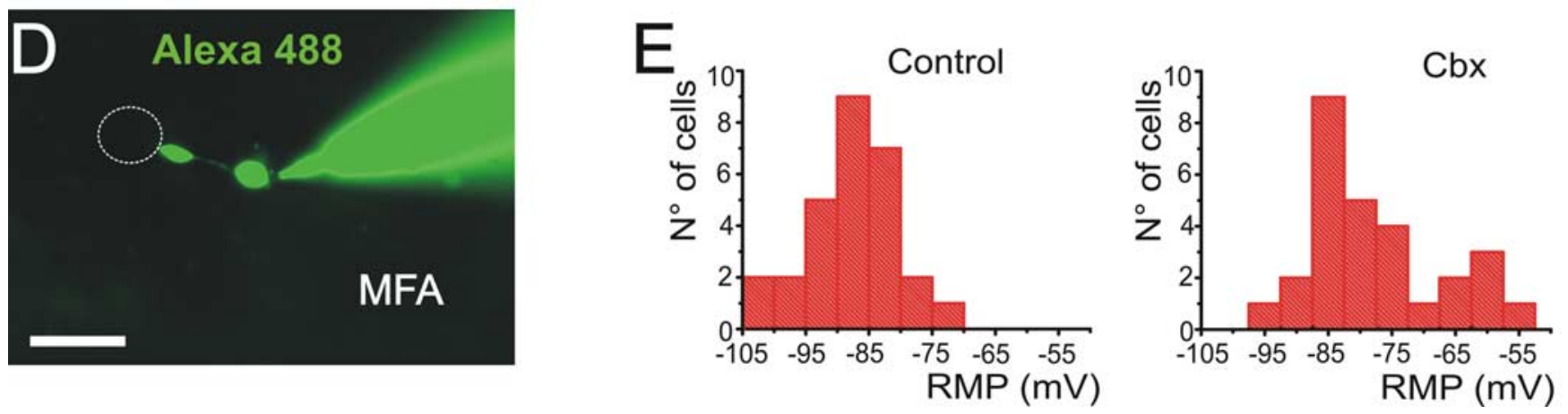

Figure 2. Functional properties of cells in the lateral CG. A, Responses of a cell in the lateral CG to a series of voltage steps (1) that displayed a linear current-voltage relationship (2). After injection with Lucifer yellow (LY), the cell appeared dye coupled with neighboring cells ( 3 ; LY). Notice the ghosts of uncoupled cells (asterisks). $\boldsymbol{B}$, Cbx (100 $\mu \mathrm{m})$ increased the input resistance of cells in the lateral $\mathrm{CG}(n=33$ cells). C, Histograms showing the distribution of the input resistance in control and after uncoupling with Cbx. D, After 15 min of preincubation with MFA (100 $\mu \mathrm{m})$, patch recordings in the lateral $\mathrm{G}$ revealed single cells $(n=10)$. Notice the small rounded cell body connected by a thin process to a wide endfoot that ended on the $C($ lumen. $\boldsymbol{E}$, Histograms showing the effect of uncoupling with $\mathrm{Cbx}(100 \mu \mathrm{m})$ on the resting membrane potential (RMP). Scale bars: A3, D, $15 \mu \mathrm{m}$.

and the resulting images were acquired with an FG7 frame grabber (Scion Instruments, Frederick, MD) using NIH Image. Although leakage from the pipette was usually sufficient to get good stainings, in most cases we applied current or voltage pulses $(500 \mathrm{~ms}$ at $1 \mathrm{~Hz}$ ) after the electrophysiological characterization to iontophorize either biocytin or fluorophores. After overnight PB rinsing, the slices were blocked with $0.5 \%$ BSA in PB $(1 \mathrm{~h})$ and then incubated in a solution containing $0.3 \%$ Triton $\mathrm{X}-100$ with either the avidin-fluorophore complex (avidin-Alexa 488 or $633 ; 2 \mathrm{~h}$ ) or the biotin-avidin-HRP complex (overnight). Slices incubated with fluorophores were mounted in glycerol and examined with a confocal microscope (FV 300; Olympus, Tokyo, Japan). Slices incubated with the HRP-conjugated complex were reacted with diaminobenzidine in the presence of $\mathrm{H}_{2} \mathrm{O}_{2}$ to produce a brown precipitate. The outlines of stained cells were manually set to generate a mask from which the area of staining was calculated using Image Pro Plus (version 5.1; Media Cybernetics, Bethesda, MD). The maximum extension of staining in the rostrocaudal axis was measured with the aid of Olympus Fluoview software.
These two values were used to calculate the volume index (area $\times$ extent of staining in the $z$-axis).

Quantification procedures. Sections were serially cut, sequentially collected in numbered vials, and chosen using a generator of random numbers. The selected sections were further processed for revealing the presence of cells that have incorporated BrdU (see below). The region surrounding the CC was divided into four triangular quadrants (two laterals, one dorsal, and one ventral) covering a total area of $300 \times 100$ $\mu \mathrm{m}$ (a rectangle centered on the CC with the longest side perpendicular to the dorsal raphe) (see Fig. $1 D$, inset). The corresponding areas were calculated and the number of BrdU-labeled nuclei was counted in each quadrant. The resulting numbers were pooled in two groups: lateral (right and left) and medial (dorsal and ventral). Densities (number of nuclei/area in square micrometers) were calculated in randomly selected sections obtained from different turtles $(n=4)$. Statistical significance was estimated with a paired $t$ test at $p<0.05$.

To estimate the number of $\mathrm{BLBP}^{+}$cells that expressed Pax6, we 

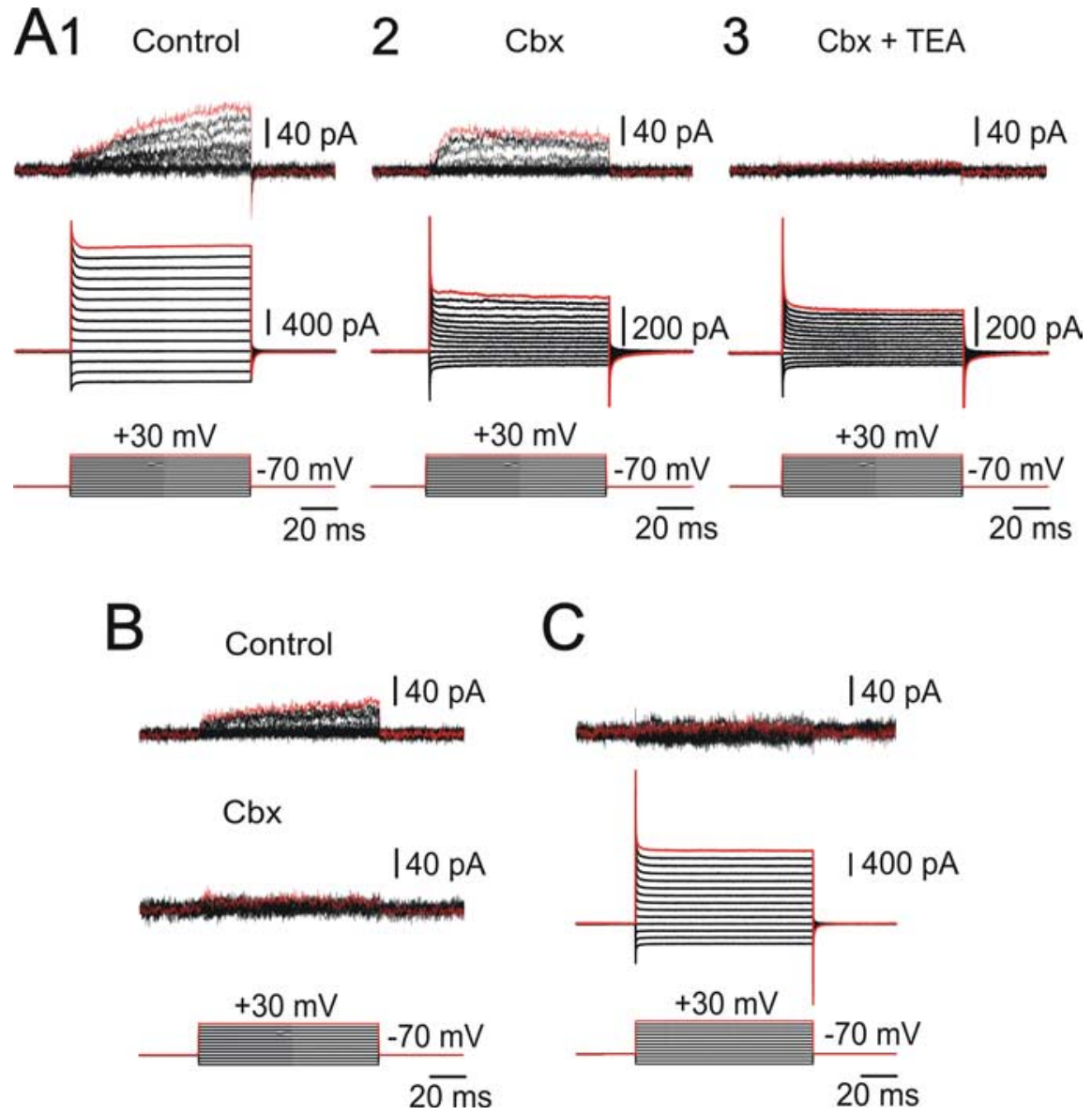

Figure 3. Clustered cells display voltage-gated outward currents. $A$, Leak-subtracted and raw currents (top and middle traces, respectively) in response to voltage steps (bottom traces). An outward current with a slow time course is observed in leaksubtracted currents (top traces; 1$)$. Cbx (100 $\mu \mathrm{m}$ ) blocked a substantial component of the total current (middle traces; 2 ) but did little to the outward current (top traces; 2). TEA (10 mM) blocked the outward current (3). B, Cell with a voltage-gated outward current (top traces) blocked by Cbx (middle traces). C, A few clusters lacked voltage-gated outward currents as shown in the leak subtracted traces (top).

counted cells from 20 confocal sections ( $1 \mu \mathrm{m}$ thick) separated $7 \mu \mathrm{m}$ from each other, obtained from the spinal cords of different turtles $(n=$ 4). To avoid cross talk, two images were recorded from each section, one scanned with the far-red light beam to excite Alexa 633, and the other with the blue light beam to excite Alexa 488. Digital images were further processed with Photoshop 7, and cells expressing both proteins (BLBP and Pax6) or only one of them counted.

Immunohistochemistry. To reveal the presence of BrdU-labeled cells, fixed 300- $\mu \mathrm{m}$-thick slices or thinner microtome sections $(60-80 \mu \mathrm{m}$ thick) were rinsed in $\mathrm{PB}$ and incubated in $2 \mathrm{~N} \mathrm{HCl}$ with proteinase $\mathrm{K}$ at 0.2 $\mathrm{mg} / \mathrm{ml}$ for $10 \mathrm{~min}$. After several rinses, sections were blocked with $5 \%$ goat serum in PBS with $0.3 \%$ Triton X-100 and placed overnight in mouse anti-BrdU (DakoCytomation, Glostrup, Denmark) diluted 1:500 in PB and $0.3 \%$ Triton X-100 (Sigma-Aldrich). After washing, the tissues were incubated with a secondary serum conjugated with a fluorophore (Alexa 488, Alexa 546, or Alexa 633; Invitrogen).

To identify the molecular phenotype of cells in the central gelatinosa (CG), we used the following primary antibodies: (1) anti-BLBP (rabbit polyclonal, 1:1000; Chemicon International, Temecula, CA), (2) anti$\mathrm{HuC} / \mathrm{D}$ (mouse monoclonal, 1:50; Invitrogen), (3) anti-Cx26 (rabbit polyclonal, 1:25; Zymed, San Francisco, CA), (4) anti-Cx43 (rabbit polyclonal, 1:3000; kindly provided by Dr. J. C. Sáez, Pontificia Universidad Católica de Chile, Santiago, Chile), (5) anti-vimentin [mouse, 40E-C raised against canary brain, 1:10; Developmental Studies Hybridoma Bank (DSHB), Iowa City, IA], (6) anti-3CB2 (mouse, 1:10; DSHB), (7) anti-Pax6 (mouse, 1:10; DSHB), and (8) anti-GFAP (rabbit polyclonal, 1:500; Sigma-Aldrich).
Tissues were placed in PB with $0.3 \%$ Triton $\mathrm{X}-100$ for $30 \mathrm{~min}$ and then incubated with the primary antibody diluted in the blocking solution. Incubation times were optimized for each antibody. In the particular case of $\mathrm{Cx} 26$, the sections were previously immersed in citrate buffer $(10 \mathrm{~mm})$ at $80^{\circ} \mathrm{C}$ for $30 \mathrm{~min}$ to retrieve the epitope. After washing in PBS, tissues were incubated in secondary antibodies conjugated with different fluorophores. When performing colabeling experiments, Alexa 488 and 633 were used to avoid cross talk. We made control experiments suppressing primary antibodies during tissue processing.

Complementary histological procedures. Cell clusters were usually examined in transverse spinal cord slices. However, in some cases $(n=5)$, slices containing well stained clusters were embedded in a mixture of agar and albumin hardened with $1 \%$ glutaraldehyde dissolved in PB. The resulting blocks were oriented in a vibrating microtome to obtain sections parallel to the longitudinal axis of the $\mathrm{CC}$ and perpendicular to the transverse plane.

To reveal the characteristics of nuclei in animals that have not received BrdU, sections were stained with the nuclear stain Syto 64 (Invitrogen).

\section{Results}

The central gelatinosa is a niche of proliferating cells

The CG is a complex region surrounding the CC that contains cells with the ability to proliferate and immature neurons, suggesting the persistence of neurogenesis after birth (Fernández et al., 2002; Russo et al., 2004; Trujillo-Cenóz et al., 2007). In other neurogenic niches, precursor cells cluster in spatially defined domains (Doetsch et al., 1997); therefore, we asked whether precursors in the CG are spatially grouped or located evenly around the CC. To reveal the population of cycling cells in the CG, we used a BrdU saturation protocol ( $n=4$ turtles) that consisted of an injection $(50 \mu \mathrm{g} / \mathrm{g})$ every $4 \mathrm{~h}$ during $24 \mathrm{~h}$ (Fig. $1 \mathrm{~A}$ ). Although we found $\mathrm{BrdU}^{+}$nuclei in all quadrants of the CG, the density of BrdU-labeled nuclei was significantly higher in the lateral quadrants (lateral quadrants: $1.31 \times 10^{-4} \pm 0.18 \times 10^{-4} \mathrm{nuclei} / \mu \mathrm{m}^{2}$; medial quadrants: $0.10 \times 10^{-4} \pm 0.04 \times 10^{-4}$ nuclei $/ \mu \mathrm{m}^{2} ; n=38$ sections; $p<$ 0.01 , paired $t$ test) (Fig. $1 B, D$ ). Close inspection of the BrdUlabeled nuclei showed that some exhibited a punctate pattern, whereas others appeared uniformly stained (data not shown). To exclude that nuclei with chromatin granules may reflect cell injury induced by BrdU, we stained spinal cord sections from noninjected turtles with the nuclear dye Syto 64 and found that a similar chromatin distribution also occurred in nontreated animals (data not shown). As reported by Cameron and McKay (2001) in the dentate gyrus of rodents, the presence of punctate nuclei cannot be attributed to a toxic action of BrdU but merely reflects "the clumping of a large proportion of the DNA into heterochromatin" replicated at the end of S-phase (Lima-de-Faria and Jaworska, 1968). We occasionally found typical mitosis close to the CC lumen (Fig. $1 C$, main image and inset), suggesting that, as in the neural 

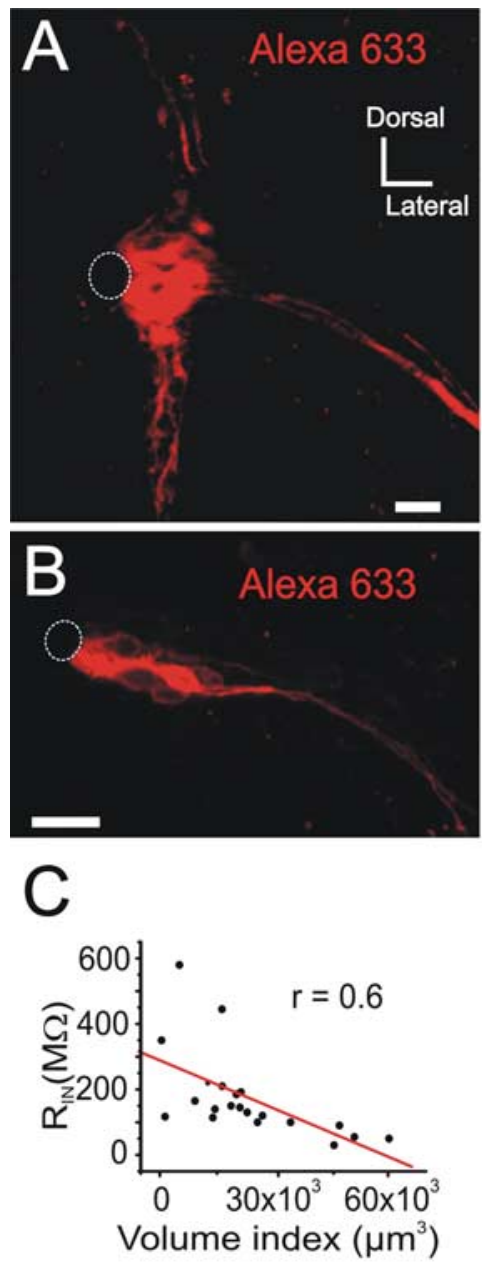
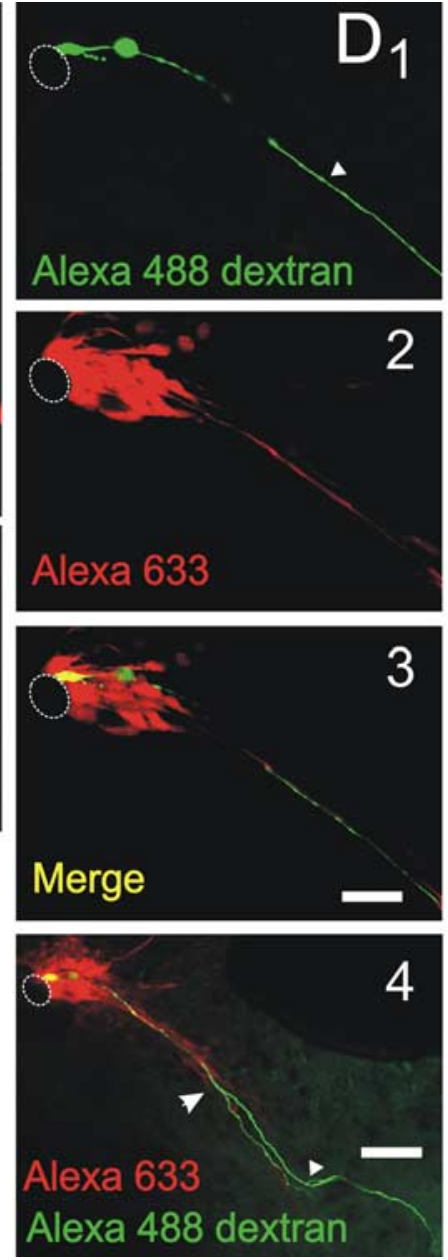
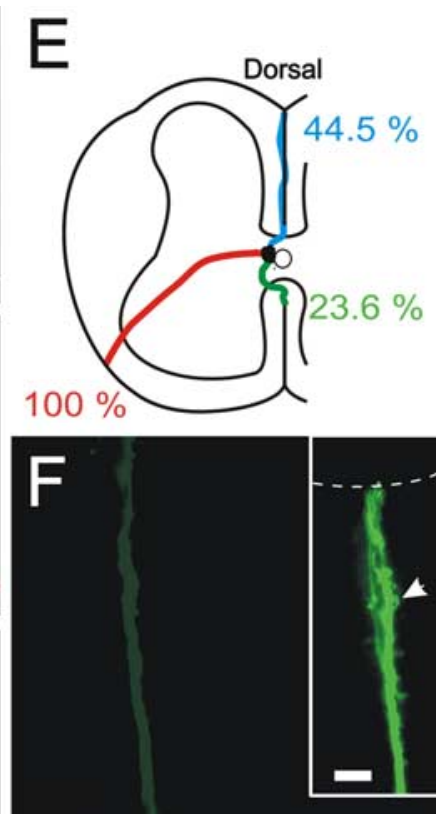

Alexa 488
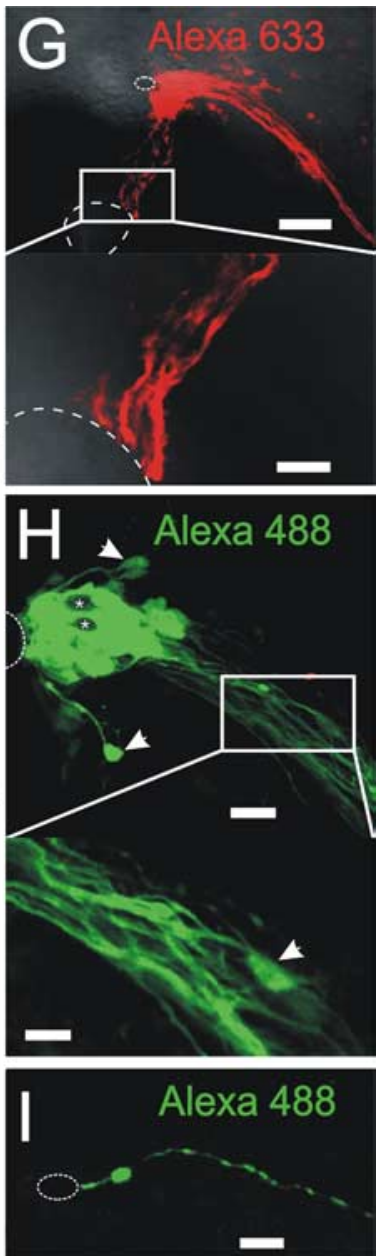

Figure 4. Clusters are diverse and contain RGs.A, A massive group of dye-coupled cells covering a whole lateral $C G$ region. Notice the three projections of fibers arising from the core of the cluster. $B$, Small cluster covering $\sim 10 \mathrm{~min}$ of the $C\left(\right.$ with only a bundle of processes projecting ventrolaterally. $C$, Inverse linear relationship between the input resistance $\left(R_{\mathbb{I N}}\right)$ and volume index (area $X$ extent of staining in the z-axis). D, Clustered cells have the typical morphology of RGs. The injection of the nonpermeable dye Alexa 488 dextran (molecular weight, 10,000) revealed a cell with bipolar morphology (1) bearing a central process that contacted the $C($ and a peripheral process that projected ventrolaterally to the pia matter (arrowhead). Injection of biocytin (revealed with streptavidin-Alexa 633) showed that the cell belonged to a cluster of dye-coupled cells $(2,3)$. The distal process of the recorded cell ran together with other processes from coupled cells $(4$, arrows). 1-3 are confocal optical sections, whereas 4 is a stack of sections. $E$, Schematic drawing showing the proportion (percentage of total number of clusters) of the projections to the pia in the surface of the cord. $\boldsymbol{F}$, A cluster with conspicuous processes running in the dorsal raphe that terminated in endfeet contacting the pia (inset). The processes had some spine-like sprouts and varicosities (arrow). G, Cluster with ventrolateral and ventral projections reaching the medial sulcus. The enlarged area shows the contact of the processes with the pia at the sulcus level. $\boldsymbol{H}$, Cell bodies (arrows) detached from the main cluster of cells. The arrow in the enlarged area shows (in a different focal plane) a cell body intermingled with the bundle of processes. $I$, A cell with RG morphology that appeared uncoupled in the lateral CG. Scale bars: $\boldsymbol{A}, 30 \mu \mathrm{m} ; \boldsymbol{B}, \mathbf{D 1}-\mathbf{D 3}, 20 \mu \mathrm{m} ; \mathbf{D} 4,50 \mu \mathrm{m} ; \boldsymbol{F}$, main image, $25 \mu \mathrm{m}$; inset, $5 \mu \mathrm{m} ; \boldsymbol{G}$, main image, $60 \mu \mathrm{m}$; enlarged area, $10 \mu \mathrm{m} ; \boldsymbol{H}$, main image, 20 $\mu \mathrm{m}$; enlarged area, $10 \mu \mathrm{m} ; l, 10 \mu \mathrm{m}$.

tube, nuclei migrate toward the CC lumen to divide (Sauer, 1935).

\section{Functional phenotype of precursor cells in the lateral CG}

Both in the embryonic and adult neurogenic niches (Lledo et al., 2006), precursor cells have a characteristic electrophysiological signature. To explore the functional phenotype of putative precursors in the lateral aspects of the CG, we made patch-clamp recordings of cells surrounding the CC. Figure $2 A$ shows the response of a representative cell to hyperpolarizing and depolarizing voltage steps (Fig. $2 A 1$ ) with a linear $I-V$ relationship (Fig. $2 A 2)$. The cells in the lateral quadrants of the CG had input resistances ranging from 7.6 to $700 \mathrm{M} \Omega$ (mean \pm SEM, $167 \pm 16$ $\mathrm{M} \Omega ; n=102)$ and resting potentials from -50 to $-104 \mathrm{mV}$ $(-87.4 \pm 1.1 \mathrm{mV} ; n=96)$. As revealed by injection of Lucifer yellow, the cell in Figure $2 \mathrm{~A}$ had a small round cell body connected to the CC by a single thin process that terminated on a wider endfoot (Fig. 2A3). The recorded cell was dye coupled to other neighbors forming a compact cluster of cells (Fig. $2 \mathrm{A3}$ ) that surrounded noncoupled elements (Fig. 2A3, asterisks). The dye coupling and low input resistance of these cells may arise from extensive electrical and metabolic coupling via gap junctions. In line with this, the gap junction decoupler carbenoxolone (100 $\mu \mathrm{M})$ significantly increased the input resistance of cells located in the lateral CG $(102.3 \pm 12.1 \mathrm{M} \Omega$ for control and $780.8 \pm 89.9$ $\mathrm{M} \Omega$ after $100 \mu \mathrm{M} \mathrm{Cbx} ; n=34 ; p<0.01$, independent $t$ test) (Fig. $2 B, C)$. Blockade of hemichannels was unlikely to contribute to the effect of carbenoxolone on the $R_{\mathrm{IN}}$ because most should be closed at the extracellular $\mathrm{Ca}^{2+}$ concentrations used in this study (Sáez et al., 2005). Therefore, the increase in $R_{\mathrm{IN}}$ induced by carbenoxolone can be attributed to the uncoupling of the recorded cells from their neighbors. In support of this possibility, incubation of slices in MFA ( $100 \mu \mathrm{M} ; n=10)$ or carbenoxolone (100 $\mu \mathrm{M} ; n=3$ ) before patch-clamp recordings in the lateral quadrants blocked dye coupling. Figure $2 D$ shows a cell with a small rounded cell body connected to a wide endfoot by a thin 
process, which was recorded after 15 min of preincubation with MFA. Notice that the gap junction permeable dye Alexa 488 failed to reveal dye coupling in the presence of MFA. In line with this, the $R_{\mathrm{IN}}$ of cells recorded in the presence of MFA was $1.96 \pm 0.27$ $\mathrm{G} \Omega$. Uncoupling with carbenoxolone also depolarized the resting membrane potential of recorded cells from an average value of $-88.1 \pm 1.3$ to $-77.7 \pm 1.9(n=30 ; p<0.01$, independent $t$ test $)$ (Fig. 2E)

Some precursors in neurogenic niches of the developing and adult brain display voltage-gated outward currents (Bahrey and Moody, 2003; Liu et al., 2006). Because small voltage-gated currents may be outweighed by leak currents, we used a leak subtraction protocol to explore the presence of active conductances in clustered cells. Figure 3 shows leak subtracted and non-leaksubtracted currents in response to depolarizing and hyperpolarizing voltage steps, from a holding potential of $-70 \mathrm{mV}$. Leak subtraction revealed that most cell clusters ( 46 of 50) displayed an outward current $(65.5 \pm 8.6 \mathrm{pA}$; peak current at $+30 \mathrm{mV})$ in response to depolarizing steps (Fig. $3 A 1$, top trace). Carbenoxolone $(100 \mu \mathrm{M})$ substantially reduced the currents in non-leaksubtracted traces (Fig. 3A2, middle trace) and decreased the peak current of the leak-subtracted traces by $\sim 50 \%(34.7 \pm 5.3 \mathrm{pA}$ at $+30 \mathrm{mV} ; p<0.05$, Wilcoxon's matched-pairs test) (Fig. 3A2, top trace). In the presence of carbenoxolone, the time course of the outward current was faster than under control conditions, presumably because of a better space clamp when the recorded cell was uncoupled from its neighbors. TEA $(10 \mathrm{~mm})$ reduced the small outward current (Fig. 3A3), suggesting the involvement of a $\mathrm{K}^{+}$delayed rectifier. In some clusters ( 6 of 21 ), carbenoxolone blocked the outward current (Fig. 3B) indicating a passive behavior of the recorded cell, whereas still in other clusters ( 4 of 50) leak subtraction did not reveal any active current (Fig. 3C).

\section{Clusters contain RGs}

Although Lucifer yellow or Alexa 488 allowed the visualization of the recorded cell and its coupled neighbors, the histochemical development of intracellularly injected biocytin permitted a more thorough analysis of the morphology of cell clusters. The size of clusters varied from a massive group of cells that covered a whole lateral CG quadrant (Fig. $4 A$ ) to rather small conglomerates of cells (Fig. $4 \mathrm{~B}$ ). The rostrocaudal extension of these clusters varied between 8.9 and $47 \mu \mathrm{m}(21.4 \pm 2.1 \mu \mathrm{m} ; n=26)$. Because the number of cells within clusters was difficult to estimate (even with nuclear stains) due to the intimate association between dye coupled cells, we calculated a volume index (area in the transverse plane $\times$ depth in the rostrocaudal axis) as a measure of cluster size. The volume index correlated inversely with the input resistances of recorded cells (Fig. $4 C$ ), suggesting that the low input resistance arose mainly from the number of coupled cells. There was no correlation between the duration of the recording and the size of the cluster, indicating that even the shortest recordings were enough to stain properly all coupled cells.

To better visualize the morphology of individual cells within clusters, we combined biocytin injection with Alexa 488 dextran, which does not permeate through gap junctions. This approach revealed that cells $(n=6)$ within clusters had the typical bipolar morphology of RGs, with a short apical process terminating on a wide endfoot that contacted the CC (Fig. 4D1-D3) (see also Fig. $2 D$ ) and a long process reaching the subpial surface (Fig. 4D1,D4, arrowheads). The distal processes of many cells joined to form bundles that projected ipsilaterally to three well defined places: the ventrolateral aspect of the lateral funiculus $(100 \% ; n=72)$ and the dorsal (44.5\%) and ventral (23.6\%) raphes (Fig. $4 E)$. All
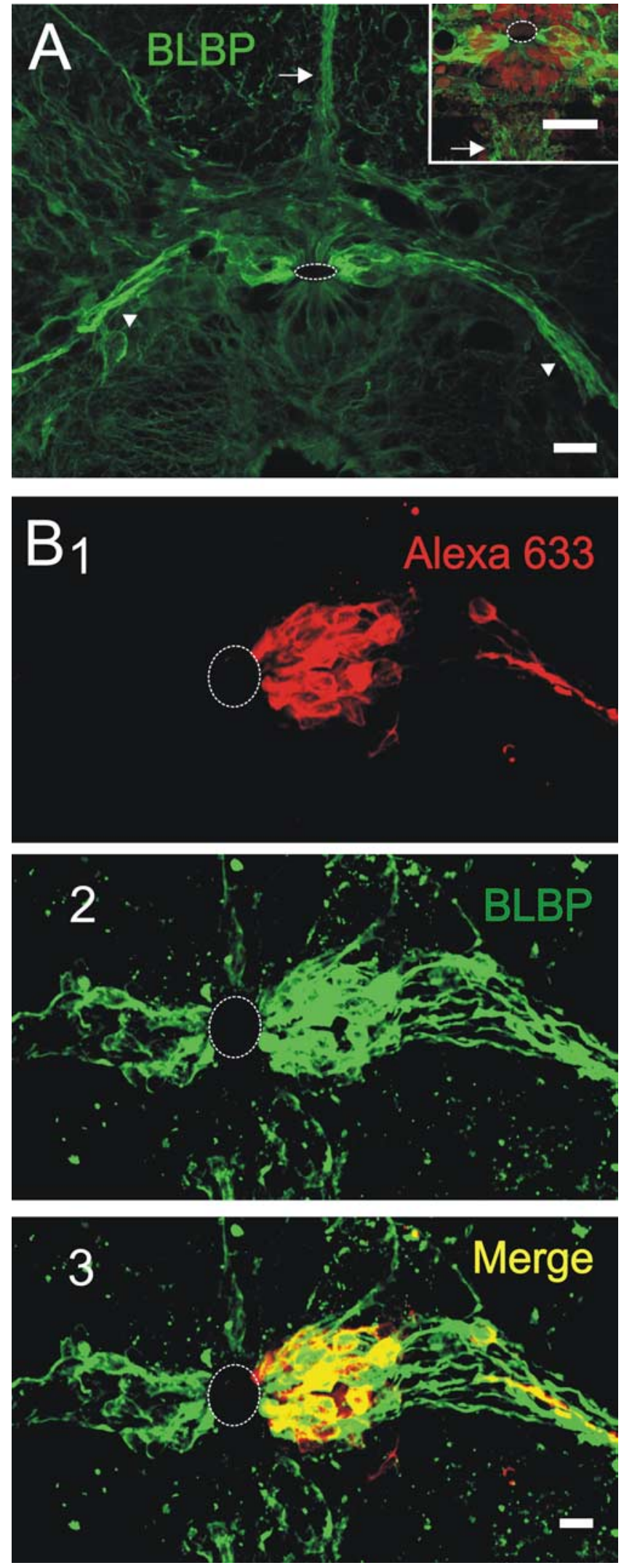

Figure 5. Clusters of coupled cells express BLBP.A, BLBP expression matched the location of clusters of gap junction coupled cells. Notice that, similarly to clusters, there were conspicuous $\mathrm{BLBP}^{+}$fibers running in the dorsal raphe (arrow) and projecting ventrolaterally (arrowheads). In some sections, a bundle of $\mathrm{BLBP}^{+}$fibers also projected to the ventral sulcus (arrow in inset). Syto 64 was used to stain nuclei in the inset. $\boldsymbol{B}$, Confocal optical sections showing a biocytinfilled cluster (1) and BLBP staining (2). The merged images show that the cells within the cluster expressed BLBP. Scale bars: $\boldsymbol{A}, 40 \mu \mathrm{m}$; inset, $10 \mu \mathrm{m} ; \boldsymbol{B}, 5 \mu \mathrm{m}$. 

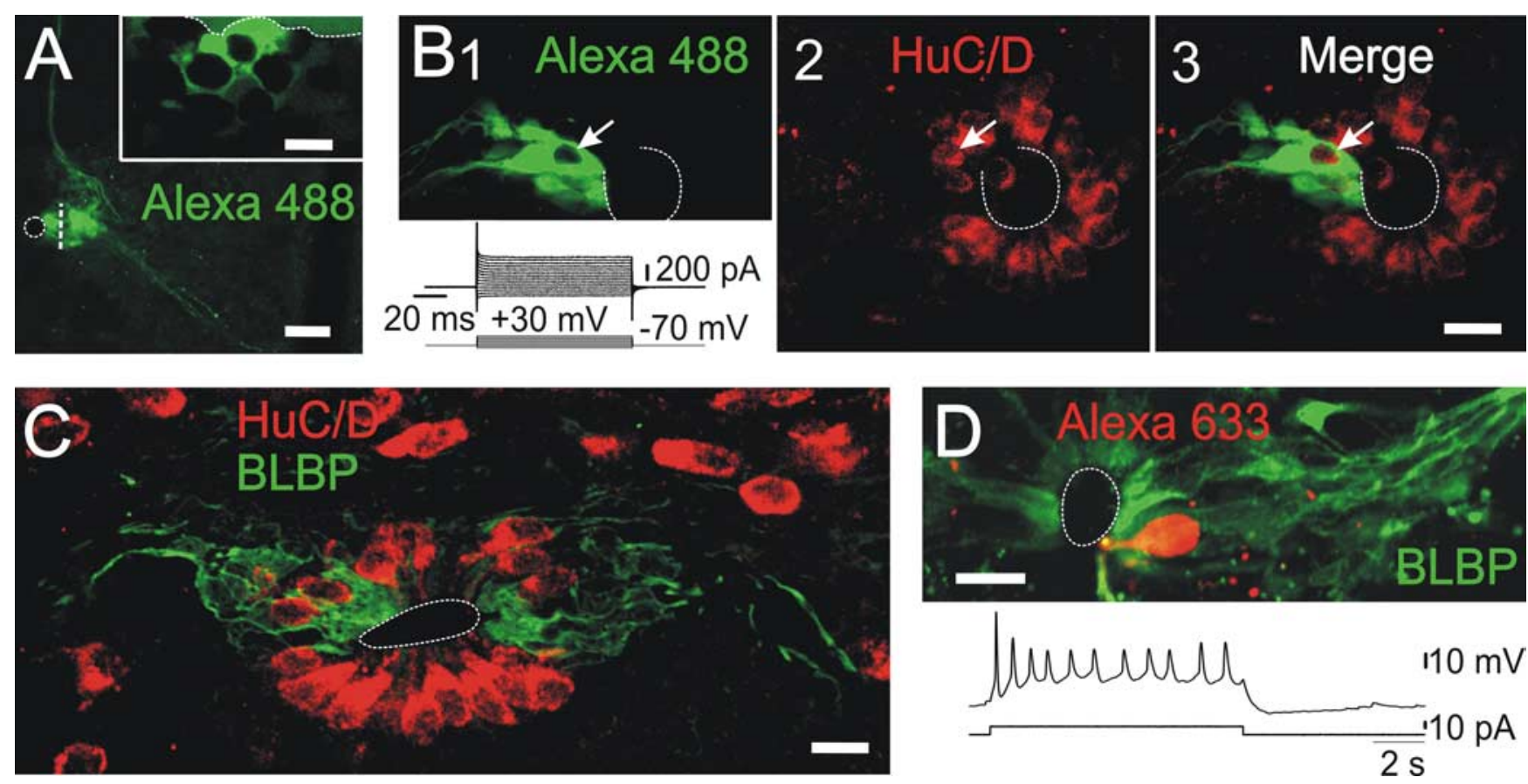

Figure 6. BLBP clustered cells and neuroblasts. $A$, A cluster of dye-coupled cells resectioned in the parasagittal planes. The inset shows a section at the level of the white line in the main image. Notice the mesh-like structure formed by gap junction coupled cells that surrounded noncoupled cells. B, Biocytin-filled cluster with the typical functional phenotype of precursor cells (1). The arrow points to a cell profile that did not belong to the cluster. In the same confocal section, the early neuronal marker HuC/D expressed in cells around the CC (2). The merged images show that the $\mathrm{HuC/D^{+ }}$ cell pointed by the arrow (2) was surrounded by the cluster (3). Also notice the lack of colocalization indicating the neuroblasts are not coupled to putative precursors (3). C, BLBP and $\mathrm{HuC} / D$ immunohistochemistry showing the intimate spatial relationship between $B L B P{ }^{+}$precursors and neuroblasts. $D, A$ biocytin-filled neuroblast able to generate action potentials surrounded by BLBP ${ }^{+}$cells. Scale bars: $A, 50 \mu \mathrm{m}$; inset, $10 \mu \mathrm{m} ; \boldsymbol{B}, \boldsymbol{C}, 20 \mu \mathrm{m} ; \boldsymbol{D}, 10 \mu \mathrm{m}$.

three projection patterns could be observed in a single cluster (Fig. 4A) (16.7\%), but most clusters showed the ventrolateral projection either alone $(48.6 \%)$ (Fig. $4 B, D, H)$ or together with the projection to the dorsal raphe (27.8\%) (Fig. $4 F)$. As described in the developing cortex (Noctor et al., 2002), the distal processes had varicosities (Fig. $4 F$, arrow in inset) and terminated on endfeet touching a limited region of the pial surface (Fig. $4 F, G$, insets).

Although clusters appeared as unitary cell assemblies, "detached cells" lying aside the main cellular mass were often observed in biocytin-filled clusters (Fig. $4 \mathrm{H}$, arrows). In some cases, cell bodies located far away from the $\mathrm{CC}$ within the bundle of fibers radiating from the cluster (Fig. $4 \mathrm{H}$, arrow in inset).

Occasionally, we found uncoupled cells in the lateral CG with the typical morphology of RGs $(n=13)$ (Fig. $4 I)$. For comparison with the lateral CG, we made some recordings in the medial quadrants. We found that in the medial CG nonspiking cells also had the morphological phenotype of RGs, with an endfoot on the $\mathrm{CC}$ and a distal process running in the ventral (supplemental Fig. $1 A$, available at www.jneurosci.org as supplemental material) or dorsal raphe (supplemental Fig. $1 B, C$, available at www. jneurosci.org as supplemental material) that reached the pia. Most cells in the medial CG appeared uncoupled (supplemental Fig. $1 A, B$, available at www.jneurosci.org as supplemental material) (11 of 19 cells), whereas the rest belonged to paucicellular clusters composed of only two to five cells (supplemental Fig. 1C, available at www.jneurosci.org as supplemental material) (8 of 19 cells).

\section{Molecular phenotype of spinal precursors}

Our data indicate that some of the cells in the lateral CG display functional and morphological characteristics of RGs. Thus, we explored the expression of molecules known to be expressed in these cells (Pinto and Götz, 2007). We previously reported that $\mathrm{GFAP}^{+}$cells predominate in the roof of the CC, whereas $\mathrm{S} 100^{+}$ cells express evenly around the $\mathrm{CC}$ alternating with $\mathrm{HuC} / \mathrm{D}^{+}$ immature neurons (Trujillo-Cenóz et al., 2007). GFAP, 3CB2, and vimentin, which express in some precursor cells in the brain (Campbell and Götz, 2002), appeared mostly in fibers throughout the CG but did not colocalize with cells within clusters (supplemental Fig. 2, available at www.jneurosci.org as supplemental material). However, BLBP expressed strongly in the lateral aspects of the CG at all levels of the spinal cord (Fig. 5A). Bundles of $\mathrm{BLBP}^{+}$fibers ran within the dorsal raphe (Fig. $5 A$, arrow) and to the lateral aspect of the cord (Fig. $5 A$, arrowheads). In some sections, $\mathrm{BLBP}^{+}$processes appeared projecting to the ventral sulcus (Fig. 5A, arrow in inset). This pattern of BLBP expression strongly resembled the extensive clusters of coupled cells. To test whether electrically coupled cells expressed BLBP, we combined the recording of cells in the lateral CG with immunostaining for BLBP. Indeed, Figure $5 B$ shows that the cells of a biocytin-filled cluster (Fig. 5B1) expressed BLBP (Fig. 5B2,B3).

\section{BLBP clustered cells and neuroblasts}

In other neurogenic niches, precursor cells envelope neuroblasts in a way that suggests an active signaling between these two cell types (Doetsch et al., 1997; Campbell, 2003; Wurmser et al., 2004). Furthermore, the expression of BLBP in RGs depends critically on signaling from neighbor developing neurons (Feng and Heintz, 1995). When clusters were sectioned following parasagittal planes (Fig. 6A), it became evident that coupled cells formed a three-dimensional network with channels occupied by unstained, uncoupled cells (Fig. 6A, inset). We hypothesized that the uncoupled cells engulfed by clusters were immature neurons. 

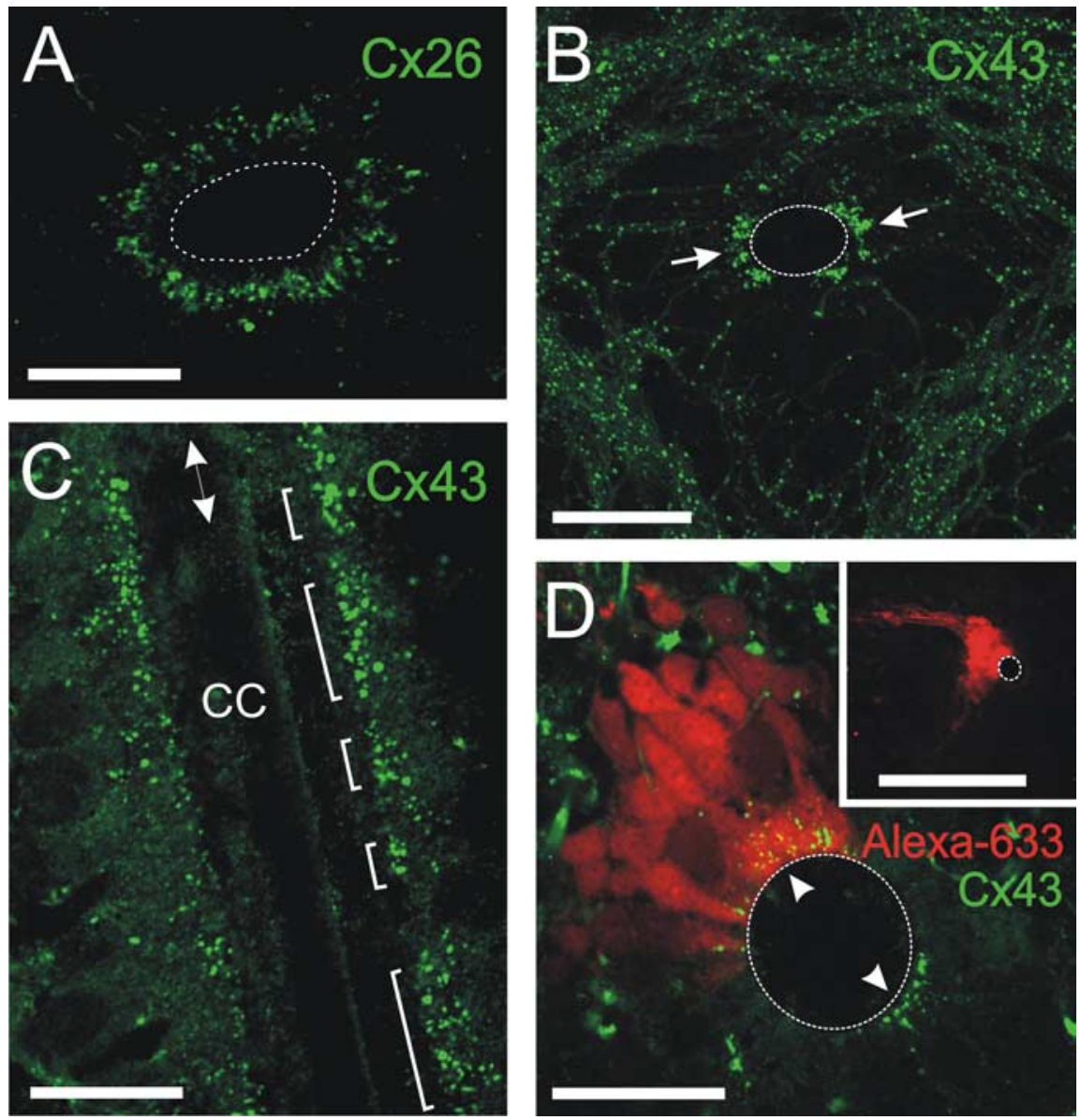

Figure 7. Molecular basis of gap junction coupling of spinal precursors. $A$, Cx26 puncta form a ring around the CC. $B$, Large aggregates of $\mathrm{C} \times 43$ puncta concentrate in the lateral aspects of the $(\mathrm{G}$ in close apposition with the $\mathrm{C} C$ lumen (arrows). Notice the lack of $\mathrm{Cx} 43$ puncta in the dorsal and ventral aspects of the $C(. C$, A longitudinal section at the level of the $C($ showing the discrete distribution of $\mathrm{C} x 43$ puncta (brackets) along the rostrocaudal axis (double-headed arrow). D, (x43 puncta localize on the apical segments of gap junction coupled cells. Notice the $\mathrm{X} \times 43$ puncta (arrowheads) on the symmetrical lateral aspect of the CC (confocal optical section). The inset shows a stack of sections of the same cluster. Scale bars: $\boldsymbol{A}, 20 \mu \mathrm{m} ; \boldsymbol{B}, 30 \mu \mathrm{m} ; \boldsymbol{C}, 20 \mu \mathrm{m} ; \boldsymbol{D}, 20 \mu \mathrm{m}$; inset, $100 \mu \mathrm{m}$.

To test this idea, we combined the recording and morphological identification of clusters with immunostaining for the early neuronal marker HuC/D. Figure $6 B$ shows a confocal optical section of a biocytin-filled cluster in which a "hole" is evident (Fig. 6 B1, arrow). The same section illuminated with the $633 \mathrm{~nm}$ laser revealed a crown of $\mathrm{HuC} / \mathrm{D}^{+}$neuroblasts surrounding the $\mathrm{CC}$ (Fig. $6 \mathrm{B2}$ ). As shown in the merged image, the $\mathrm{HuC} / \mathrm{D}^{+}$cell pointed by the arrow was surrounded by the cluster (Fig. $6 \mathrm{B3}$, arrow). Similarly, $\mathrm{BLBP}^{+}$cells surrounded $\mathrm{HuC} / \mathrm{D}^{+}$putative immature neurons (Fig. 6C). Although $\mathrm{HuC} / \mathrm{D}$ is an early neuronal marker, this protein is also expressed in a subset of neuronal progenitors in the embryonic cerebral cortex (Miyata et al., 2004). Thus, to confirm that the $\mathrm{HuC} / \mathrm{D}^{+}$cells immersed within $\mathrm{BLBP}^{+}$clustered cells were indeed immature neurons, we recorded from cells in the lateral CG with the characteristic morphology of neuroblasts as visualized under DIC optics (Russo et al., 2004). Figure $6 \mathrm{D}$ shows a cell that fired action potentials in response to a depolarizing current pulse surrounded by $\mathrm{BLBP}^{+}$cells.

Molecular basis of gap junction coupling of spinal precursors The current electrophysiological data and our previous electron microscope studies (Trujillo-Cenóz et al., 2007) point to the existence of gap junctions connecting adjoining RGs in the spinal cord. Although several connexins are expressed in the developing brain, $\mathrm{Cx} 26$ and $\mathrm{Cx} 43$ are the main subtypes in the subventricular zone of the developing forebrain (Nadarajah et al., 1997; Bittman and Lo Turco, 1999). Therefore, to address their possible involvement in gap junction coupling among spinal precursors, we performed immunocytochemistry against Cx26 and Cx43. Cx26 puncta appeared forming a ring around the CC (Fig. 7A). The high concentration of $\mathrm{Cx} 26$ puncta appeared at $5 \mu \mathrm{m}$ from the CC lumen and extended rather symmetrically $\sim 5 \mu \mathrm{m}$ toward the periphery (Fig. 7A). Therefore, although we cannot rule out a contribution of $\mathrm{Cx} 26$ to coupling, its spatial distribution cannot explain the selective location of extensive clusters on the lateral quadrants. We also found $\mathrm{Cx} 43$ puncta widely distributed both in the gray and white matter of the spinal cord. Remarkably, a high density of puncta appeared close to the CC lumen on the lateral quadrants of the CC (Fig. $7 B$, arrows). This high density of puncta was absent in the dorsal and ventral aspects of the CC. We next examined longitudinal sections of the cord to explore the distribution of the Cx43 along the rostrocaudal axis. Interestingly, we found discrete aggregations of Cx43-labeled puncta whose lengths in the rostrocaudal dimension ranged from 6 to $42 \mu \mathrm{m}(14.7 \pm 3.3 \mu \mathrm{m}$; $n=11$ ) (Fig. 7C). These findings suggest that the distribution of $\mathrm{Cx} 43$ may account for the extension of cell clusters both in the transverse plane and the rostrocaudal axis. To test whether there was actually a topological correspondence between the high concentration of $\mathrm{Cx} 43$ close to the CC lumen and the distribution of dye-coupled cells, we combined patch recordings and biocytin staining of clusters with immunohistochemistry for $\mathrm{Cx} 43$. Our results evidenced a close spatial correspondence consistent with the hypothesis that cell coupling within clusters is mediated by $\mathrm{Cx} 43$ gap junctions concentrated on the endfeet of CC contacting cells (Fig. 7D). Together, our results show that, although both $\mathrm{Cx} 26$ and $\mathrm{Cx} 43$ express in the CG, the spatial distribution of these connexins suggests that $\mathrm{Cx} 43$ is the subtype that delimits the clusters in the lateral quadrants of the CG.

\section{$\mathrm{BLBP}^{+}$clusters contain dividing cells}

Our results indicate that, in the CG, the highest rate of proliferation occurs in the lateral quadrants in which cells with the functional, morphological, and molecular features of RGs form domains of electrically coupled cells. We hypothesized that, as in the developing cortex (Bittman et al., 1997), these clusters contain mitotically active cells. To test this possibility, we combined a saturation protocol of BrdU with immunohistochemistry for BLBP and patch-clamp recordings of cell clusters. We found that clusters contained between one (one of six clusters) and two cells (five of six) that incorporated BrdU (Fig. 8A,B). As expected by the correlation between cell cluster and BLBP expression in the 
lateral CG, mitotically active cells that incorporated BrdU expressed BLBP (Fig. $8 C)$.

\section{Pax6 expression in cell clusters}

The data shown above suggested that $\mathrm{BLBP}^{+}$RGs may be progenitors with the potential to generate cells that differentiate to the neuronal lineage. Because Pax6 has been identified as an important regulator of neurogenic RGs (Pinto and Götz, 2007), we then explored the expression of this transcription factor. Remarkably, Pax6 expressed selectively on the lateral CG, matching the location of $\mathrm{BLBP}^{+}$clustered cells (Fig. 9A). To test whether clusters actually contained Pax $6^{+}$cells, we then combined patch-clamp recordings with Pax6 immunohistochemistry. Figure 9 shows a biocytin-filled cluster (Fig. 9B1, main image and inset) and Pax6 expression in the same optical section (Fig. 9B2). As evidenced by the merged images (Fig. 9B3), some cells within the cluster expressed Pax6. To quantify the population of $\mathrm{BLBP}^{+}$cells that also expressed Pax6, we combined immunohistochemistry for these markers (Fig. 9C1-C3). We found that the vast majority of $\mathrm{BLBP}^{+}$cells expressed Pax6 (486 of $493 \mathrm{BLBP}^{+}$cells). Conversely, most $\mathrm{Pax}^{+}$cells were also $\mathrm{BLBP}^{+}$(486 of $548 \mathrm{Pax}^{+}$cells). Together, these data indicate that the majority of $\mathrm{BLBP}^{+}$cells in the lateral CG represent a neurogenic subtype of RGs. Our previous study (Fernández et al., 2002) showing that NeuN, a marker of mature neurons, colo-
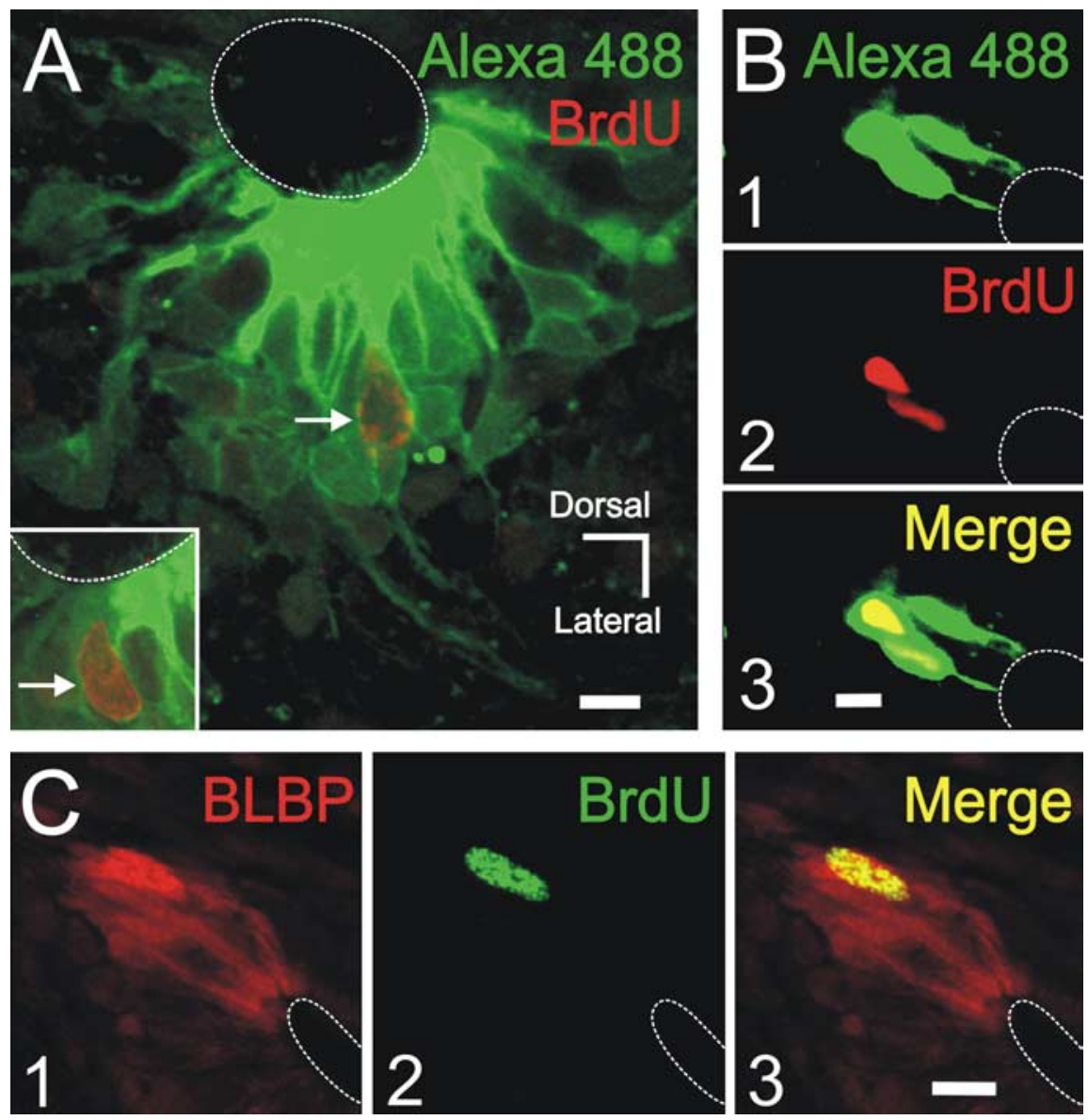

Figure 8. $\quad \mathrm{BLBP}^{+}$clusters contain dividing cells. $A$, Large cluster of dye-coupled cells containing a BrdU-labeled nucleus (arrow). The inset shows in another confocal plane of the same cluster a $\mathrm{BrdU}^{+}$nucleus close to the $\mathrm{CC}$ lumen. $\mathrm{B}, \mathrm{A}$ small cluster of three cells (1) with two BrdU ${ }^{+}$nuclei (2). C, BLBP ${ }^{+}$group of cells (1) in the lateral CG. A BrdU ${ }^{+}$nucleus overlapped the $\mathrm{BLBP}^{+}$field (2). The merged images show that the $\mathrm{BrdU}^{+}$nucleus belonged to a $\mathrm{BLBP}^{+}$cell. All images are confocal optical sections. Scale bars: $A, B, 5 \mu \mathrm{m} ; C, 10 \mu \mathrm{m}$. calizes with BrdU after long survival times

(50-70 d), supports this possibility. Lineage analysis with retroviral vectors would help to define the potential of these precursors and to characterize their functional differentiation toward postmitotic cells.

\section{Discussion}

We show here that, in the turtle spinal cord, there is a niche in which cells proliferate actively and display properties of neural precursors. Proliferating cells concentrated on the lateral CG belonged to clusters electrically and metabolically coupled via Cx43. The bipolar morphology and expression of BLBP indicated that these cells represent a subtype of RGs (Pinto and Götz, 2007) with electrophysiological properties similar to precursors found in neurogenic zones of the forebrain (Noctor et al., 2002; Filippov et al., 2003; Wang et al., 2003; Liu et al., 2006). The expression of Pax6 supports the persistence of postnatal neurogenic domains, a property that may be related with the remarkable ability of low vertebrates to recover after spinal cord injury.

\section{Cell proliferation and gap junction coupling}

Although we found proliferating cells around all the CG, their number was significantly higher in the lateral quadrants. This may arise from different cell cycle lengths or just to a particular lateral location of proliferating cells. Although in this study we did not address possible differences in cell cycle length, our data suggest that proliferating cells in the medial and lateral quadrants of the CG are indeed different. Patch-clamp recordings revealed extensive dye coupling in the lateral CG only, suggesting electrical and metabolical coupling via gap junctions. Dye-coupled cell clusters had low $R_{\mathrm{IN}}$ and an electrophysiological phenotype dominated by leak currents, thus resembling the properties of precursor cells in the developing cortex (Noctor et al., 2001, 2002) and type- 1 precursors in the adult hippocampus (Filippov et al., $2003)$. The low $R_{\mathrm{IN}}$ of clusters arose mainly from the number of coupled precursors because the $R_{\mathrm{IN}}$ of individual cells in the presence of carbenoxolone was about an order of magnitude higher than that of clusters, suggesting a rather high coupling coefficient among clustered cells.

Gap junction coupling seems a general feature among some precursors in the developing brain (Lo Turco and Kriegstein, 1991; Bittman et al., 1997) and the adult subventricular zone (Liu et al., 2006). Consistently, cell clusters in the spinal cord of the turtle appeared in the region with the highest density of $\mathrm{BrdU}^{+}$ cells, suggesting some relationship between proliferation of spinal precursors and gap junction coupling. This is supported by the fact that clusters contained mitotically active cells. Similar findings were reported in the ventricular zone of the developing cortex in which coupling is needed to allow cells entering the S-phase (Bittman et al., 1997). Our results suggest that gap junc- 

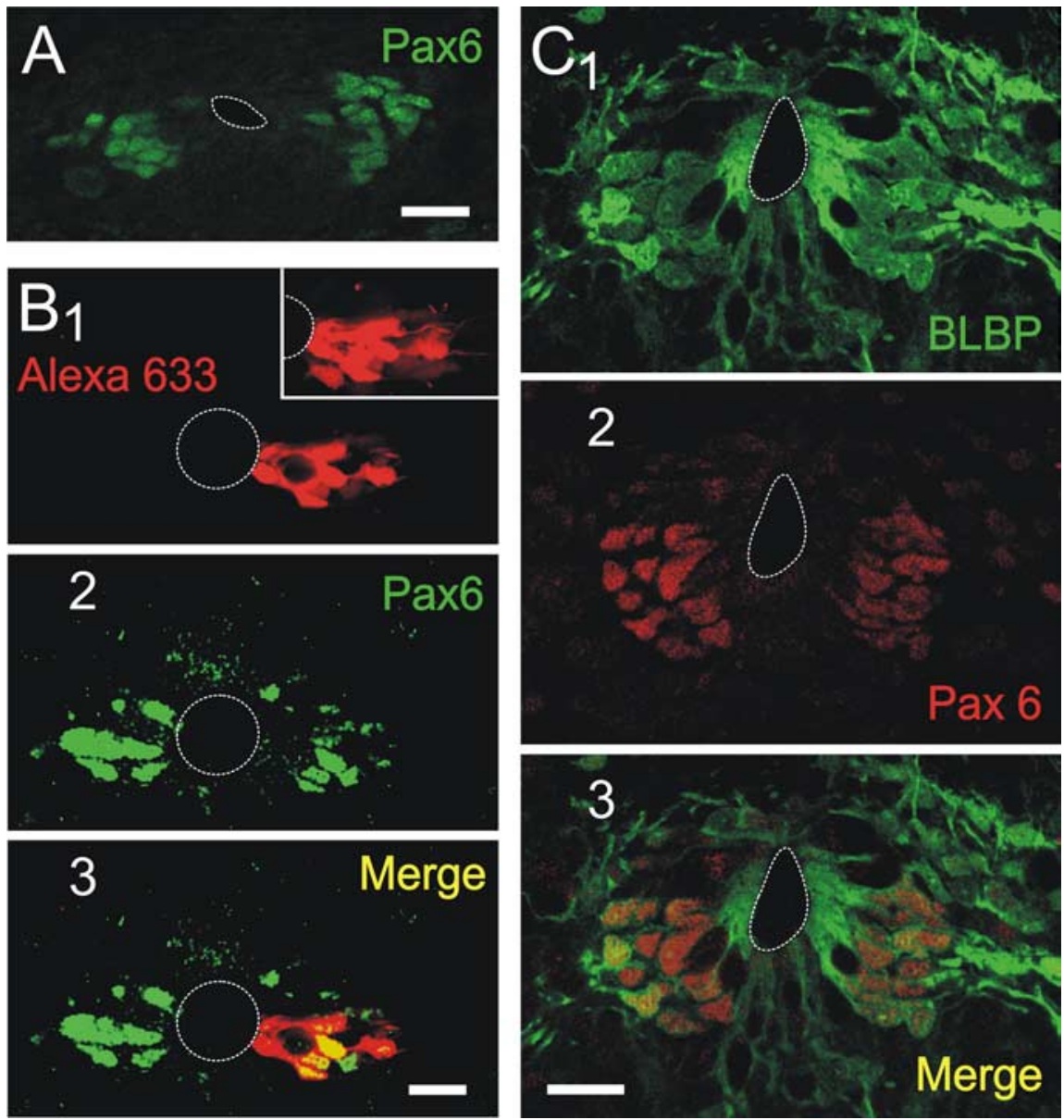

Figure 9. Pax6 is expressed in BLBP clustered cells. $A$, Pax 6 expression matched the location of clusters of $\mathrm{BLBP}^{+}$cells. $\boldsymbol{B}$, The combination of patch recording with biocytin staining (1) and immunocytochemistry for Pax6 (2) shows that clustered precursors expressed the transcription factor Pax6 (3). The inset in $\boldsymbol{B} 1$ is a stack of sections showing the whole cluster of dye-coupled cells. The main images are confocal optical sections. C, BLBP (1) and Pax6 (2) expression in the CG. The merged images show that most $\mathrm{BLBP}^{+}$cells coexpressed Pax6 (3). Scale bars: $A, 30 \mu \mathrm{m} ; \boldsymbol{B}, \mathbf{C}, 20 \mu \mathrm{m}$.

tion coupling may be a general mechanism related to the proliferation of precursors in different species and regions of the CNS.

\section{Electrophysiological signature of clustered precursors}

The $R_{\mathrm{IN}}$ of spinal precursor cells after uncoupling varied widely. Interestingly, the middle and high range of $R_{\mathrm{IN}}$ were similar to those reported in the postnatal subventricular zone for $\mathrm{GFAP}^{+}$ precursors $(\approx 300 \mathrm{M} \Omega$ ) (Liu et al., 2006) and neuronal progenitors $(\approx 4 \mathrm{G} \Omega$ ) (Wang et al., 2003), respectively. Like precursors in the subventricular zone of the adult rat (Wang et al., 2003; Liu et al., 2006) and the cortex of the mouse embryo (Bahrey and Moody, 2003), most cell clusters displayed a voltage-dependent TEA-sensitive current suggesting the presence of delayed $\mathrm{K}^{+}$ channels. However, some clustered cells had a passive behavior as in RGs of the ventricular zone (Noctor et al., 2002). Thus, clusters seem integrated by heterogeneous electrophysiological phenotypes, including cells displaying only leak currents coupled to others with various degrees of expression of a delayed rectifier.

The electrophysiological heterogeneity of clustered cells may reflect functional states related to different phases of the cell cycle, the dynamics of cell maturation or heterogeneity in neural precursors. For example, in mesenchymal stem cells, both the membrane potential and a delayed rectifier change during the cell cycle (Deng et al., 2007). $\mathrm{K}^{+}$channels regulate cell proliferation, prob- ably by regulating cell volume and membrane potential (Pardo, 2004). Indeed, delayed outward-rectifying $\mathrm{K}^{+}$currents (Kv1.3 subunit) are essential for $\mathrm{G}_{1} / \mathrm{S}$ transition and thus proliferation of oligodendrocyte progenitors (Chittajallu et al., 2002). It is tempting to speculate that a delayed rectifier may also play a part in the control of proliferation of spinal precursors, a possibility that remains to be experimentally tested.

\section{Cx43 spatially delimits the domains of precursors}

Connexins play an important role in the regulation of proliferation, migration, and differentiation (Bruzzone and Dermietzel, 2006), with both $C x 43$ and Cx26 expressing differentially during development $(\mathrm{Na}$ darajah et al., 1997; Bittman and Lo Turco, 1999). Although Cx26 expressed in the CG, our results indicate that $\mathrm{Cx} 43$ played a major role in coupling spinal precursors. This finding is in line with the recognized role of $\mathrm{Cx} 43$ in maintaining neural progenitors in a proliferative state (Duval et al., 2002; Cheng et al., 2004).

Cx43 concentrated on the apical poles of RGs that contacted the lateral aspects of the CC, thus providing the molecular basis that determined the location of clusters. This adds to the molecular polarity of RGs (Chenn et al., 1998), which is thought to have critical functional consequences (Götz and Huttner, 2005). The apical segment of progenitors has been proposed to sense signals that regulate cell proliferation and differentiation (Alvarez-Buylla et al., 2001; Pinto and Götz, 2007). Thus, the strong metabolical coupling of spinal precursors at their apical poles may allow an efficient communication of molecules regulating cell division or cellular differentiation (Bruzzone and Dermietzel, 2006). In addition, the apical pole of RGs has a set of molecules whose inheritance according to the plane of cleavage during division determines the fate of daughter cells (Götz and Huttner, 2005). We hypothesize that $\mathrm{Cx} 43$ in apical segments, is ideally located to be one of the key molecules whose symmetric or asymmetric inheritance may decide the fate of daughter cells. If the cleavage plane is not parallel to the RG main axis, one daughter cell may not inherit $\mathrm{Cx} 43$ and then will be uncoupled. This latter cell may differentiate to a postmitotic glia or neuron because uncoupling is correlated with differentiation (Duval et al., 2002; Bruzzone and Dermietzel, 2006). Connexins have been recently shown to be involved in migration of cells along RG processes in the developing cortex (Elias et al., 2007). In line with this, we observed dye-coupled cells intermingled with RG processes (Fig. $4 H$, inset), suggesting that they may be cells migrating away from the CG. Cx43 and Cx26 may also affect the proliferation, migration, and differentiation of spinal precursors by nonconventional mechanisms via molecular interactions with a variety of proteins (Kardami et al., 2007). Interestingly, the role of connexins in migration during development is actually mediated 
by facilitation of cell-cell adhesion and not by their functions as channels (Elias et al., 2007).

\section{A neurogenic domain of RGs in the spinal cord}

As in the postnatal brain of the mouse (Merkle et al., 2007), the distal projections of clustered RGs to spatially restricted loci may reflect some kind of positional information defining precursors with different potentialities. In a previous study, we showed that the distal endfeet of RGs have infolds suggesting some form of communication between RGs and the basal membrane (TrujilloCenóz et al., 2007). The apposition of the distal process with the subpial basal membrane is claimed to be important to maintain the neurogenic capabilities of precursor cells (Alvarez-Buylla and Lim, 2004). Therefore, the contact with the pia of some cells within biocytin-filled clusters fulfills another criterion of a neurogenic precursor.

RGs represent a heterogenous population showing diverse molecular signatures with different potential to proliferate and lineage differentiation (Campbell and Götz, 2002; Pinto and Götz, 2007). In the CG, BLBP expression matched the location of clusters of gap junction coupled cells, which formed a tridimensional network that enveloped immature neurons, a finding consistent with the intimate relationship needed for signaling between RGs and differentiating neurons (Feng and Heintz, 1995). It has been proposed that RGs expressing BLBP behave as bipotent or multipotent precursor cells (Hartfuss et al., 2001; Pinto and Götz, 2007), raising the possibility that clusters in the lateral quadrant of the CG represent discrete neurogenic domains. The fact that some $\mathrm{BLBP}^{+}$clustered cells also expressed Pax6, a transcription factor identified as a key regulator of the subset of neurogenic RGs (Heins et al., 2002; Pinto and Götz, 2007), supports our hypothesis of a neurogenic domain in the lateral CG. In the spinal cord, Pax6 is part of a transcriptional code defining progenitor domains from which subtypes of spinal neurons are generated (Lee and Pfaff, 2001). The expression of Pax6 in cells lining the CC decreases as development proceeds (Fu et al., 2003) and is not detected in the adult mammalian cord (Yamamoto et al., 2001). However, spinal cord injury induces the reexpression of Pax6 in ependymal cells and promotes cell division (Yamamoto et al., 2001). The fact that Pax6 expression persists in neurogenic niches of the adult mammalian brain (Kohwi et al., 2005; Nacher et al., 2005) suggests a role for this transcription factor in postnatal neurogenesis, and supports the idea that the turtle spinal cord preserves the remarkable plasticity to generate new neurons for integration to already operating spinal circuits.

\section{References}

Alvarez-Buylla A, Lim DA (2004) For the long run: maintaining germinal niches in the adult brain. Neuron 41:683-686.

Alvarez-Buylla A, García-Verdugo JM, Tramontin AD (2001) A unified hypothesis on the lineage of neural stem cells. Nat Rev Neurosci 2:287-293.

Bahrey HL, Moody WJ (2003) Voltage-gated currents, dye and electrical coupling in the embryonic mouse neocortex. Cereb Cortex 13:239-251.

Barry PH, Diamond JM (1970) Junction potentials, electrode standard potentials, and other problems in interpreting electrical properties in membranes. J Membr Biol 3:93-122.

Bittman K, Owens DF, Kriegstein AR, Lo Turco JJ (1997) Cell coupling and uncoupling in the ventricular zone of developing neocortex. J Neurosci 17:7037-7044.

Bittman KS, Lo Turco JJ (1999) Differential regulation of connexin 26 and 43 in murine neocortical precursors. Cereb Cortex 9:188-195.

Bruzzone R, Dermietzel R (2006) Structure and function of gap junctions in the developing brain. Cell Tissue Res 326:239-248.

Cameron HA, McKay RD (2001) Adult neurogenesis produces a large pool of new granule cells in the dentate gyrus. J Comp Neurol 435:406-417.
Campbell K (2003) Signaling to and from radial glia. Glia 43:44-46.

Campbell K, Götz M (2002) Radial glia: multipurpose cells for vertebrate brain development. Trends Neurosci 25:235-238.

Cheng A, Tang H, Cai J, Zhu M, Zhang X, Rao M, Mattson MP (2004) Gap junctional communication is required to maintain mouse cortical neural progenitor cells in a proliferative state. Dev Biol 272:203-216.

Chenn A, Zhang YA, Chang BT, McConnell SK (1998) Intrinsic polarity of mammalian neuroepithelial cells. Mol Cell Neurosci 11:183-193.

Chittajallu R, Chen Y, Wang H, Yuan X, Ghiani CA, Heckman T, McBain CJ, Gallo V (2002) Regulation of Kvl subunit expression in oligodendrocyte progenitor cells and their role in $G_{1} / S$ phase progression of the cell cycle. Proc Natl Acad Sci USA 99:2350-2355.

Danilov AI, Covacu R, Moe MC, Langmoen IA, Johansson CB, Olsson T, Brundin L (2006) Neurogenesis in the adult spinal cord in an experimental model of multiple sclerosis. Eur J Neurosci 23:394-400.

Deng XL, Lau CP, Lai K, Cheung KF, Lau GK, Li GR (2007) Cell cycledependent expression of potassium channels and cell proliferation in rat mesenchymal stem cells from bone marrow. Cell Prolif 40:656-670.

Doetsch F, García-Verdugo JM, Alvarez-Buylla A (1997) Cellular composition and three-dimensional organization of the subgerminal zone in the adult mammalian brain. J Neurosci 17:5046-5061.

Duval N, Gomes D, Calaora V, Calabrese A, Meda P, Bruzzone R (2002) Cell coupling and $\mathrm{Cx} 43$ expression in embryonic mouse neural progenitor cells. J Cell Sci 115:3241-3251.

Elias LA, Wang DD, Kriegstein AR (2007) Gap junction adhesion is necessary for radial migration in the neocortex. Nature 448:901-907.

Feng L, Heintz N (1995) Differentiating neurons activate transcription of the brain lipid-binding protein gene in radial glia through a novel regulatory element. Development 121:1719-1730.

Feng L, Hatten ME, Heintz N (1994) Brain lipid-binding protein (BLBP): a novel signaling system in the developing mammalian CNS. Neuron 12:895-908.

Fernández A, Radmilovich M, Trujillo-Cenoz O (2002) Neurogenesis and gliogenesis in the spinal cord of turtles. J Comp Neurol 458:293-306.

Filippov V, Kronenberg G, Pivneva T, Reuter K, Steiner B, Wang LP, Yamaguchi M, Kettenmann H, Kempermann G (2003) Subpopulation of nestin-expressing progenitor cells in the adult murine hippocampus shows electrophysiological and morphological characteristics of astrocytes. Mol Cell Neurosci 23:373-382.

Fu H, Qi Y, Tan M, Cai J, Hu X, Liu Z, Jensen J, Qiu M (2003) Molecular mapping of the origin of postnatal spinal cord ependymal cells: evidence that adult ependymal cells are derived from Nkx6.1+ ventral progenitor cells. J Comp Neurol 456:237-244.

Götz M, Huttner WB (2005) The cell biology of neurogenesis. Nat Rev Mol Biol 6:777-788.

Hartfuss E, Galli R, Heins N, Gotz M (2001) Characterization of CNS precursor subtypes and radial glia. Dev Biol 229:15-30.

Heins N, Malatesta P, Cecconi F, Nakafuku M, Tucker KL, Hack MA, Chapouton P, Barde YA, Gotz M (2002) Glial cells generate neurons: the role of the transcription factor Pax6. Nat Neurosci 5:308-315.

Horner PJ, Power AE, Kempermann G, Kuhn HG, Palmer TD, Winkler J, Thal LJ, Gage FH (2000) Proliferation and differentiation of progenitor cells throughout the intact adult rat spinal cord. J Neurosci 20:2218-2228.

Kardami E, Dang X, Iacobas DA, Nickel BE, Jeyaraman M, Srisakuldee W, Makazan J, Tanguy S, Spray DC (2007) The role of connexins in controlling cell growth and gene expression. Prog Biophys Mol Biol 94:245-264.

Kohwi M, Osumi N, Rubenstein JL, Alvarez-Buylla A (2005) Pax6 is required for making specific subpopulations of granule and periglomerular neurons in the olfactory bulb. J Neurosci 25:6997-7003.

Lee SK, Pfaff SL (2001) Transcriptional networks regulating neuronal identity in the developing spinal cord. Nat Neurosci 4:1183-1191.

Lima-de-Faria A, Jaworska H (1968) Late DNA síntesis in heterochromatin. Nature 217:138-142.

Liu X, Bolteus AJ, Balkin DM, Henschel O, Bordey A (2006) GFAPexpressing cells in the postnatal subventricular zone display a unique glial phenotype intermediate between radial glia and astrocytes. Glia 54:394-410.

Lledo PM, Alonso M, Grubb MS (2006) Adult neurogenesis and functional plasticity in neuronal circuits. Nat Rev Neurosci 7:179-193.

Lo Turco JJ, Kriegstein AR (1991) Clusters of coupled neuroblasts in embryonic neocortex. Science 252:563-565. 
Merkle FT, Mirzadeh Z, Alvarez-Buylla A (2007) Mosaic organization of neural stem cells in the adult brain. Science 317:381-384.

Ming GL, Song H (2005) Adult neurogenesis in the mammalian central nervous system. Annu Rev Neurosci 28:223-250.

Miyata T, Kawaguchi A, Saito K, Kawano M, Muto T, Ogawa M (2004) Asymmetric production of surface-dividing and non-surface-dividing cortical progenitor cells. Development 131:3133-3145.

Mothe AJ, Tator CH (2005) Proliferation, migration, and differentiation of endogenous ependymal region stem/progenitor cells following minimal spinal cord injury in the adult rat. Neuroscience 31:177-187.

Nacher J, Varea E, Blasco-Ibanez JM, Castillo-Gomez E, Crespo C, MartinezGuijarro FJ, McEwen BS (2005) Expression of the transcription factor Pax 6 in the adult rat dentate gyrus. J Neurosci Res 81:753-761.

Nadarajah B, Jones AM, Evans WH, Parnavelas JG (1997) Differential expression of connexins during neocortical development and neuronal circuit formation. J Neurosci 17:3096-3111.

Noctor SC, Flint AC, Weissman TA, Dammerman RS, Kriegstein AR (2001) Neurons derived from radial glial cells establish radial units in neocortex. Nature 409:714-720.

Noctor SC, Flint AC, Weissman TA, Wong WS, Clinton BK, Kriegstein AR (2002) Dividing precursor cells of the embryonic cortical ventricular zone have morphological and molecular characteristics of radial glia. J Neurosci 22:3161-3173.

Nowakowski RS, Lewin SB, Miller MW (1989) Bromodeoxyuridine immunohistochemical determination of the lengths of the cell cycle and the DNA-synthetic phase for an anatomically defined population. J Neurocytol 18:311-318.
Pardo LA (2004) Voltage-gated potassium channels in cell proliferation. Physiology 19:285-292.

Pinto L, Götz M (2007) Radial glial cell heterogeneity—-the source of diverse progeny in the CNS. Prog Neurobiol 83:2-23.

Russo RE, Fernández A, Reali C, Radmilovich M, Trujillo-Cenóz O (2004) Functional and molecular clues reveal precursor-like cells and immature neurons in the turtle spinal cord. J Physiol (Lond) 560:831-838.

Sáez JC, Retamal MA, Basilio D, Bukauskas FF, Bennett MV (2005) Connexin-based gap junction hemichannels: gating mechanisms. Biochim Biophys Acta 1711:215-224.

Sauer FC (1935) Mitosis in the neural tube. J Comp Neurol 62:377-405.

Taupin P (2007) BrdU immunohistochemistry for studying adult neurogenesis: paradigms, pitfalls, limitations, and validation. Brain Res Rev 53:198-214.

Trujillo-Cenóz O, Fernández A, Radmilovich M, Reali C, Russo RE. (2007) Cytological organization of the central gelatinosa in the turtle spinal cord. J Comp Neurol 502:291-308.

Wang DD, Krueger DD, Bordey A (2003) Biophysical properties and ionic signature of neuronal progenitors of the postnatal subventricular zone in situ. J Neurophysiol 90:2291-2302.

Wurmser AE, Palmer TD, Gage FH (2004) Cellular interactions in the stem cell niche. Science 304:1253-1255.

Yamamoto S, Nagao M, Sugimori M, Kosako H, Nakatomi H, Yamamoto N, Takebayashi H, Nabeshima Y, Kitamura T, Weinmaster G, Nakamura K, Nakafuku M (2001) Transcription factor expression and Notchdependent regulation of neural progenitors in the adult rat spinal cord. J Neurosci 21:9814-9823. 